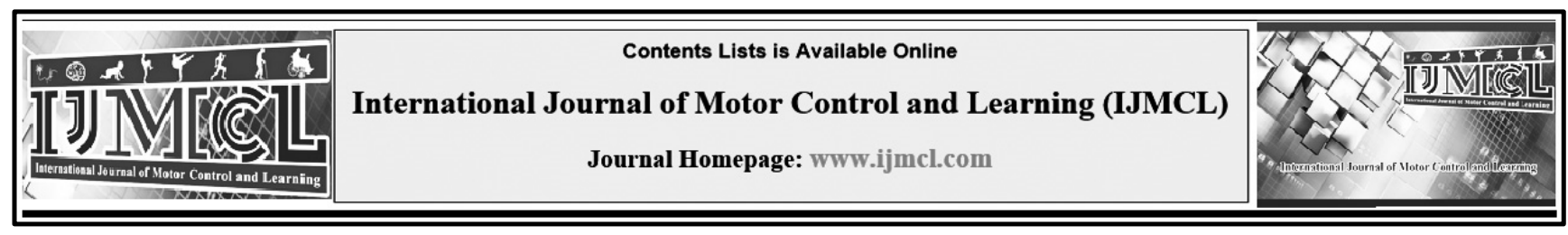

\title{
The Effects of Gender and Type of Stimulus Presentation on Serial Reaction Time
}

\author{
Mina Keshavarz ${ }^{a}$, Jalal Dehganizade ${ }^{b *}$
}

${ }^{\text {a }}$ Phd student in motor behavior, University of Urmia, Urmia, Iran

${ }^{\mathrm{b}}$ Assistant Professor of motor behavior, University of Urmia, Urmia, Iran

\begin{tabular}{l}
\hline Keywords \\
\hline Serial Reaction Time \\
Sex Difference \\
Orderly Stimulus \\
Disorderly Stimulus
\end{tabular}

Jalal Dehganizade, Email: jalal.dehghanizade@yahoo.com

Received: 2020/07/21

Accepted: 2020/10/14

Published: 2020/11/05

\begin{abstract}
Background: Serial Reaction Time (SRT) is a simple task specifically designed to examine reaction time and learn implicit sequences.

Objective: The aim of the present study was to evaluate the effect of gender (male and female) and type of stimulus (orderly and disorderly) on the serial reaction time.

Methods: The sample included 30 students of physical education (15 males \& 15 females). All subjects were right-handed and none had a history practice serial reaction time task. To measure the reaction time was used a serial-reaction time test (SRTT), that was included 8 blocks and stimulants were presented on the screen for blue, yellow, red and green and participants responded to stimuli with non-dominant hand. To investigate the effects of gender and type of stimuli was used repeated measures ANOVA test.
\end{abstract}

\begin{abstract}
Results: The results showed that gender has not significant effect on response time, but has significant effects of the stimulus presentation on reaction times and reaction time higher in stimuli disorderly.
\end{abstract}

Conclusion: The findings suggest that exercise can be effective on reaction time and eliminate gender differences in reaction time. Also, implicit learning during the implementation serial reaction time of orderly stimulus is affected in the reaction time.

\section{Introduction}

Reaction time (RT) is one of the simplest ways to assess a person's sensory and motor performance. In fact, RT is the defined time interval between the onset of stimuli and the onset of response to stimuli and is a useful indicator for studying the ability of the central nervous system (Ramanathan et al., 2019). The interval between the appearance of a visual, an auditory or a tactical stimulus and a movement, is called reaction time. Raichur (2013) claims that reaction time includes cognitive, metacognitive and kinetic functions (Raichur 2013). From a physiological point of view, RT is a complex phenomenon whose functioning has been studied by numerous researchers (Kuang, 2017). Many researchers believe that the RT depends on the speed of the sensorimotor cycle, composed by the detection of the initial stimulus, transfer of the information through the afferent nerves, generation of the response from the central nervous system, and final response (Adleman et al.,2016; Greenhouse et al., 2017). The importance of reaction time can also be assumed in daily human activities (Reacting at a busy intersection, paying attention while driving, avoiding injuries when falling, etc.) (Balko et al., 2020). Reaction time in sport can also affect an athlete's ability to optimize performance, focus, 
and make appropriate decisions (Ali, Oueslati, \& Dugas, 2018). There are a number of factors that can change reaction time such as demographics variables like age (Atan \& Akyol, 2014, Brychta et al., 2013, Obetko et al., 2019) and gender (Lauridsen et al., 2012), physical factors such as condition (Hascelik et al., 1989) and fatigue (Sant'Ana et al., 2017), environmental factors such as altitude (Dykiert et al., 2010), and stimulant or depressant factors such as alcohol, caffeine (Martin and Garfield, 2006). According to the stimuli number we can divide the reaction time into two main groups: simple reaction time - response only to one stimulus, complex/disjunctive reaction time - a choice response, different responses to multiple stimuli (Obetko et al., 2019). The response to a particular stimulus is expressed by summing the time it receives and processes it, evaluates the appropriate solution, and the time it takes to perform a particular move (Kozina et al., 2017). reaction time is classically fractionated into two components, i.e., premotor time and motor time or electromechanical delay (EMD), in which premotor time reflects cognitive function, i.e., central components, while EMD reflects motor function, i.e., peripheral components (Le Mansec et al., 2019). Reaction speed manifests itself using reaction time and belongs to the category of genetically related physical abilities, which means that training does not have much effect on them (Obetko et al., 2019). This claim has also been confirmed by Gomez Lopez et al. (Gomez Lopez, 2017). The speed of reaction depends on three important factors: stimulus feature, response feature, and individual feature. Stimulus feature are factors that are inherent in the stimulus, such as intensity, amplitude, duration, and so on. Response feature include variables that are related to the type of response required, such as simplicity, selectivity or differentiation, and complexity and motor time. The third category of variables affecting reaction time, which are broader and more complex, are personality-related feature. Most influential variables related to the environment can be placed in this category (Wang, 2009).

serial Reaction Time (SRT) is a simple task specifically designed to examine reaction time and learn implicit sequences. The classic protocol for the SRT task requires participants to respond to a visual stimulus repeatedly shown on the screen. Stimulus presentations are usually grouped into blocks, with some blocks containing a predefined sequence whereas others containing pseudorandom sequences (Hong et al., 2020). SRT is often used in studies of stable visual attention and motor mobility (Bruinsma et al., 2019). Research on gender differences in reaction time shows that men and women receive different RTs for a variety of stimuli (Çakmakçı et al., 2019). For example, Wadoo et al. (2019) in a study examined the effect of gender and physical activity on the Adult visual and auditory reaction time and reported that there is a significant difference in RT between women and men. Balko et al. (2017) also studied the effect of a 9-week educational intervention on the reaction time of adolescents aged 15 to 18 and concluded that after exercise, the reaction time improves in both girls and boys. Spierer et al. (2010) considered a task that required a response with the foot and offered two types of auditory and 
visual stimuli. The researchers found that male athletes had a faster reaction time in auditory conditions and faster motor time in both visual and auditory conditions than female athletes. In a longitudinal study, Pancar et al. (2016) examined the simple visual and auditory reaction time of 11 to 18 year olds and concluded that there was no statistically significant difference between boys and girls, but with increasing age, both groups reacted. They do it faster. Der \& Deary (2006), Silverman (2006), Spierer et al. (2010), Bennett \& Natalie (2011) and Karia et al. (2012) have also pointed out the superiority of men over women in various tasks of simple and selective reaction time. In summary, studies show the superiority of men over simple and selective reactions over women. Given that the serial reaction time has only been studied in an animal sample (Bayless et al., 2012) . So the question still remains whether there is this superiority for men even during a serial reaction? Therefore, the aim of this study was to compare the serial reaction time of two groups of male and female student athletes.

\section{Method \\ Participants}

The research method was post event (causalcomparative). In this study 30 students (15 boys and 15 girls) were considered as a sample among physical education students. All participants were right-handed and none had a history of serial reaction training or test time. The mean age of boys was 19.58 years and girls 20.11 years. All participants were tested for the serial Reaction Time test (SSRT) in the motor Behavior
Laboratory of the Faculty of Physical Education, Urmia University, which was a quiet and convenient place.

\section{Data Gathering Tool}

After selecting the sample, Subjects participated in a serial reaction time test (SRTT). In this study, sequential reaction time software has been used. Regarding the validity and reliability of this tool, it can be said that studies have shown that this test is not dependent on culture (Robertson, 2007) and on the other hand, the recordings are done by computer and human error not involved in registration. The software is such that the stimuli appear as colored squares (yellow, green, blue and red) on the computer screen and the person must respond to the stimuli with the index finger of the dominant right hand by pressing the same color button. There are 4 buttons on the computer keyboard to respond to colors; The M button is for red, the $\mathrm{P}$ button is for blue, the $\mathrm{Z}$ button is for green and the $\mathrm{Q}$ button is for yellow, and the label for each color is affixed to it. Each block stage in this experiment consists of 8 blocks and each block contains 12 stimuli (colored square). Eventually each subject will make 120 attempts. All blocks except the first and sixth blocks followed a specific sequence. The specific sequence and pattern of appearance of the squares were yellow, green, yellow, blue, red, green and blue. The stimuli (colored squares) appeared randomly in the first and sixth blocks. In this version, in order to reduce the possibility of using explicit strategies, while performing the motor task related to implicit learning, the subject has a time interval between 
responding to one stimulus and the emergence of the next stimulus by zero, by the subject realizing the motor sequence. Approximate test time is 15 minutes. This test has no age limit and has been used in various studies in different age groups and children, including the elderly (Nejati et al., 2007), young people (Willingham et al., 2000). The time of each test step (in milliseconds) and the number of correct responses to the target stimuli are measured separately by the software. Response time (RT) is a measure of learning speed and time of correct answers (T) is a measure of learning accuracy.

\section{Implementation Method}

The method of Implementation the sequence learning task was that the participants, sat in a room with low light in front of a computer at a distance of about $90 \mathrm{~cm}$ and performed the task. The participants, was asked to press the same color key as soon as he/she saw each square. Subjects were not aware of the sequence. To motivate, the examiner used sentences between the eight blocks to encourage the participants, to complete the task.

\section{Statistical Tests}

Descriptive statistics were used to categorize the data, Shapiro-Wilk test was used to analyze the normal distribution of data, and repeated measures analysis of ANOVA test was used to examine the effect of gender and type of stimulus presentation, as well as to compare the mean of the groups. These steps were performed using SPSS 18 software and at a significant level of $\alpha=0.05$.

\section{Results}

Table 1 shows the descriptive findings of the study including central tendencies (mean), dispersion (standard deviation), maximum and minimum for response time (RT) and time of correct answers (T) variables for boys and girls separately.

Table 1. Descriptive statistics on the reaction time and the number of correct answers of boys and girls in each block.

\begin{tabular}{|c|c|c|c|c|c|c|c|c|c|}
\hline \multicolumn{2}{|c|}{ Group } & \multicolumn{4}{|c|}{ Boy } & \multicolumn{4}{|c|}{ Girl } \\
\hline Blocks & Variable & $\mathbf{M}$ & SD & $\max$ & $\min$ & $\mathbf{M}$ & SD & $\max$ & $\min$ \\
\hline \multirow{2}{*}{ one } & $\mathbf{T}$ & 114.26 & 4.183 & 101 & 118 & 111.87 & 13.212 & 68 & 119 \\
\hline & RT & 0.846 & 0.152 & 0.67 & 1.19 & 0.888 & 0.181 & 0.63 & 1.32 \\
\hline \multirow{2}{*}{ two } & $\mathbf{T}$ & 115.93 & 2.987 & 107 & 119 & 115.87 & 3.998 & 105 & 120 \\
\hline & RT & 0.763 & 0.12 & 0.6 & 1.01 & 0.836 & 0.146 & 0.69 & 1.19 \\
\hline \multirow{2}{*}{ three } & $\mathbf{T}$ & 114.93 & 3.674 & 107 & 120 & 2.386 & 2.386 & 111 & 119 \\
\hline & RT & 0.751 & 0.12 & 0.57 & 0.97 & 0.144 & 0.144 & 0.64 & 1.06 \\
\hline \multirow{2}{*}{ four } & $\mathbf{T}$ & 115.87 & 2.416 & 110 & 119 & 2.968 & 2.968 & 109 & 120 \\
\hline & RT & 0.77 & 0.12 & 0.59 & 1.00 & 0.142 & 0.142 & 0.65 & 1.1 \\
\hline \multirow{2}{*}{ five } & $\mathbf{T}$ & 115.4 & 3.247 & 107 & 119 & 3.913 & 3.913 & 105 & 119 \\
\hline & RT & 0.73 & 0.119 & 0.53 & 0.99 & 0.137 & 0.137 & 0.58 & 1.08 \\
\hline \multirow{2}{*}{ six } & $\mathbf{T}$ & 114.73 & 4.044 & 105 & 120 & 4.621 & 4.621 & 104 & 119 \\
\hline & RT & 0.789 & 0.117 & 0.59 & 1.00 & 0.133 & 0.133 & 0.68 & 1.1 \\
\hline \multirow{2}{*}{ seven } & $\mathbf{T}$ & 115.4 & 3.46 & 110 & 120 & 3.629 & 3.629 & 106 & 120 \\
\hline & RT & 0.673 & 0.107 & 0.48 & 0.85 & 0.128 & 0.128 & 0.62 & 1.02 \\
\hline \multirow{2}{*}{ eight } & $\mathbf{T}$ & 116.27 & 2.738 & 110 & 120 & 115.47 & 5.153 & 103 & 120 \\
\hline & RT & 0.658 & 0.129 & 0.45 & 0.93 & 0.694 & 0.102 & 0.6 & 0.97 \\
\hline
\end{tabular}


To investigate the normality of data distribution, Shapiro-Wilk test was used and the results are shown in Table 2.

Table 2. The results of Shapiro-Wilk test to check the normal distribution of data.

\begin{tabular}{cccccccc}
\hline \multicolumn{2}{c}{ Group } & \multicolumn{3}{c}{ Boy } & \multicolumn{3}{c}{ Girl } \\
\hline Blocks & Variable & d & Shapiro & Sig. & d & Shapiro & Sig. \\
\hline One & T & 15 & 0.922 & 0.223 & 15 & 0.925 & 0.233 \\
& RT & 15 & 0.913 & 0.151 & 15 & 0.936 & 0.340 \\
Two & T & 15 & 0.936 & 0.334 & 15 & 0.945 & 0.451 \\
& RT & 15 & 0.936 & 0.751 & 15 & 0.896 & 0.083 \\
Three & T & 15 & 0.948 & 0.499 & 15 & 0.938 & 0.364 \\
& RT & 15 & 0.894 & 0.076 & 15 & 0.912 & 0.125 \\
Five & T & 15 & 0.948 & 0.501 & 15 & 0.960 & 0.598 \\
& RT & 15 & 0.934 & 0.309 & 15 & 0.963 & 0.742 \\
Six & T & 15 & 0.882 & 0.052 & 15 & 0.943 & 0.411 \\
& RT & 15 & 0.960 & 0.695 & 15 & 0.888 & 0.061 \\
eight & T & 15 & 0.903 & 0.105 & 15 & 0.922 & 0.229 \\
& RT & 15 & 0.959 & 0.671 & 15 & 0.941 & 0.479 \\
& T & 15 & 0.968 & 0.820 & 15 & 0.892 & 0.081 \\
& RT & 15 & 0.945 & 0.447 & 15 & 0.969 & 0.711 \\
& RT & 15 & 0.951 & 0.546 & 15 & 0.908 & 0.115 \\
\end{tabular}

The contents of Table 2 show that the distribution of data in all variables and for both groups has a natural distribution $(\mathrm{P}>0.05)$.

To compare and determine the effect of gender and type of stimulus presentation (regular and irregular), repeated measures analysis of variance ANOVA test was used for response time (RT) and time of correct answers (T), the results of which are reported in Tables 3 and 4.

Table 3. Results of analysis of variance test to determine the effect of gender and type of stimulus on the time of correct answers $(T)$.

\begin{tabular}{ccccccc}
\hline Source of variation & ss & $\begin{array}{c}\text { df } \\
\text { Assumption }\end{array}$ & $\begin{array}{c}\text { df } \\
\text { Error }\end{array}$ & $\begin{array}{c}\text { Mean } \\
\text { square }\end{array}$ & f & Sig. \\
\hline Blocks & 198.763 & 7 & 196 & 81.922 & 1.995 & 0.135 \\
\hline Gender & 10.838 & 1 & 28 & 10.838 & 0.124 & 0.727 \\
\hline Block * Gender & 51.263 & 7 & 196 & 21.128 & 0.514 & 0.635 \\
\hline
\end{tabular}

The contents of Table 3 show that none of the main effects of the block $\left(\mathrm{F}_{(7,196)}=1.995 \& \mathrm{P}=0.135\right)$, gender $\left(\mathrm{F}_{(1,28)}=0.124 \& \mathrm{P}=0.727\right)$ and Also, the interaction between them $\left(\mathrm{F}_{(7,196)}=0.514 \&\right.$
$\mathrm{P}=0.635)$ in the time of correct answers $(\mathrm{T})$ is not significant.

Table 4. Results of analysis of variance test to determine the effect of gender and type of stimulus at response time

\begin{tabular}{ccccccc}
\hline \multicolumn{7}{c}{$(\mathbf{R T})}$. \\
Source of variation & ss & $\begin{array}{c}\text { df } \\
\text { Assumption }\end{array}$ & df Error & $\begin{array}{c}\text { Mean } \\
\text { square }\end{array}$ & f & Sig. \\
\hline Blocks & 0.772 & 7 & 196 & 0.202 & 43.094 & 0.001 \\
\hline Gender & 0.177 & 1 & 28 & 0.177 & 1.443 & 0.24 \\
\hline Block * Gender & 0.013 & 7 & 196 & 0.003 & 0.699 & 0.588 \\
\hline
\end{tabular}


The results of Table 4 show that only the main effect of the blocks is significant $\left(F_{(7,196)}=\right.$ $43.094 \& \mathrm{P}=0.001)$ and the main effect of gender $\left(\mathrm{F}_{(1,28)}=1.443 \& \mathrm{P}=0.24\right)$ and the interaction between test blocks and gender $(\mathrm{F}$ $(7,196)=0.699 \& \mathrm{P}=0.588)$ were not significant.
In other words, there is no effect on gender serial reaction time test and there is no significant difference between boys and girls. However, due to the effect of test blocks, pair differences between blocks can be examined.

Table 5. Comparison of pairs of blocks in response time (RT) between two groups of boys and girls.

\begin{tabular}{|c|c|c|c|c|c|c|c|}
\hline \multicolumn{2}{|c|}{ group } & \multicolumn{3}{|c|}{ Boy } & \multicolumn{3}{|c|}{ girl } \\
\hline Blocks & Blocks & md & $\begin{array}{c}\text { Standard } \\
\text { Error }\end{array}$ & Sig. & md & $\begin{array}{c}\text { Standard } \\
\text { Error }\end{array}$ & Sig. \\
\hline \multirow[t]{7}{*}{ Block 1} & 2 & 0.083 & 0.021 & 0.04 & 0.052 & 0.023 & 1.00 \\
\hline & 3 & 0.095 & 0.019 & 0.007 & 0.093 & 0.025 & 0.068 \\
\hline & 4 & 0.076 & 0.021 & 0.088 & 0.079 & 0.026 & 0.256 \\
\hline & 5 & 0.115 & 0.021 & 0.002 & 0.095 & 0.026 & 0.076 \\
\hline & 6 & 0.057 & 0.028 & 1.00 & 0.033 & 0.029 & 1.00 \\
\hline & 7 & 0.173 & 0.027 & 0.001 & 0.143 & 0.029 & 0.006 \\
\hline & 8 & 0.188 & 0.024 & 0.001 & 0.193 & 0.029 & 0.001 \\
\hline \multirow[t]{6}{*}{ Block 2} & 3 & 0.012 & 0.015 & 1.00 & 0.041 & 0.009 & 0.02 \\
\hline & 4 & -0.007 & 0.013 & 1.00 & 0.027 & 0.018 & 1.00 \\
\hline & 5 & 0.033 & 0.021 & 1.00 & 0.043 & 0.015 & 0.327 \\
\hline & 6 & -0.026 & 0.012 & 1.00 & -0.019 & 0.017 & 1.00 \\
\hline & 7 & 0.09 & 0.016 & 0.002 & 0.091 & 0.017 & 0.003 \\
\hline & 8 & 0.105 & 0.014 & 0.001 & 0.141 & 0.016 & 0.001 \\
\hline \multirow[t]{5}{*}{ Block 3} & 4 & -0.019 & 0.014 & 1.00 & -0.013 & 0.018 & 1.00 \\
\hline & 5 & 0.021 & 0.018 & 1.00 & 0.002 & 0.014 & 1.00 \\
\hline & 6 & -0.038 & 0.017 & 1.00 & -0.06 & 0.014 & 0.028 \\
\hline & 7 & 0.078 & 0.013 & 0.001 & 0.05 & 0.018 & 0.428 \\
\hline & 8 & 0.093 & 0.015 & 0.001 & 0.101 & 0.019 & 0.004 \\
\hline \multirow[t]{4}{*}{ Block 4} & 5 & 0.039 & 0.012 & 0.155 & 0.015 & 0.016 & 1.00 \\
\hline & 6 & -0.019 & 0.015 & 1.00 & -0.047 & 0.019 & 0.774 \\
\hline & 7 & 0.097 & 0.011 & 0.001 & 0.063 & 0.021 & 0.232 \\
\hline & 8 & 0.112 & 0.013 & 0.001 & 0.114 & 0.017 & 0.001 \\
\hline \multirow[t]{3}{*}{ Block 5} & 6 & -0.059 & 0.021 & 0.406 & -0.062 & 0.012 & 0.005 \\
\hline & 7 & 0.057 & 0.017 & 0.129 & 0.048 & 0.014 & 0.131 \\
\hline & 8 & 0.073 & 0.017 & 0.02 & 0.099 & 0.018 & 0.002 \\
\hline \multirow[t]{2}{*}{ Block 6} & 7 & 0.116 & 0.011 & 0.001 & 0.11 & 0.009 & 0.001 \\
\hline & 8 & 0.131 & 0.012 & 0.001 & 0.161 & 0.019 & 0.001 \\
\hline Block 7 & 8 & 0.015 & 0.011 & 1.00 & 0.051 & 0.016 & 0.277 \\
\hline
\end{tabular}

The contents of Table 5 show that there are differences between some test blocks for boys and girls, but these differences are very variable. Since the stimulus presentation was irregular in blocks 1 and 6 and regular in the rest of the blocks, it is a valuable comparison between the mentioned blocks. As Figure 1 shows, response time over eight blocks are similar for both boys and girls, although the average response time for boys in each block is less than that for girls. It is also clear that most of the response time was obtained for blocks 1 and 6 where the stimuli were presented irregularly. 


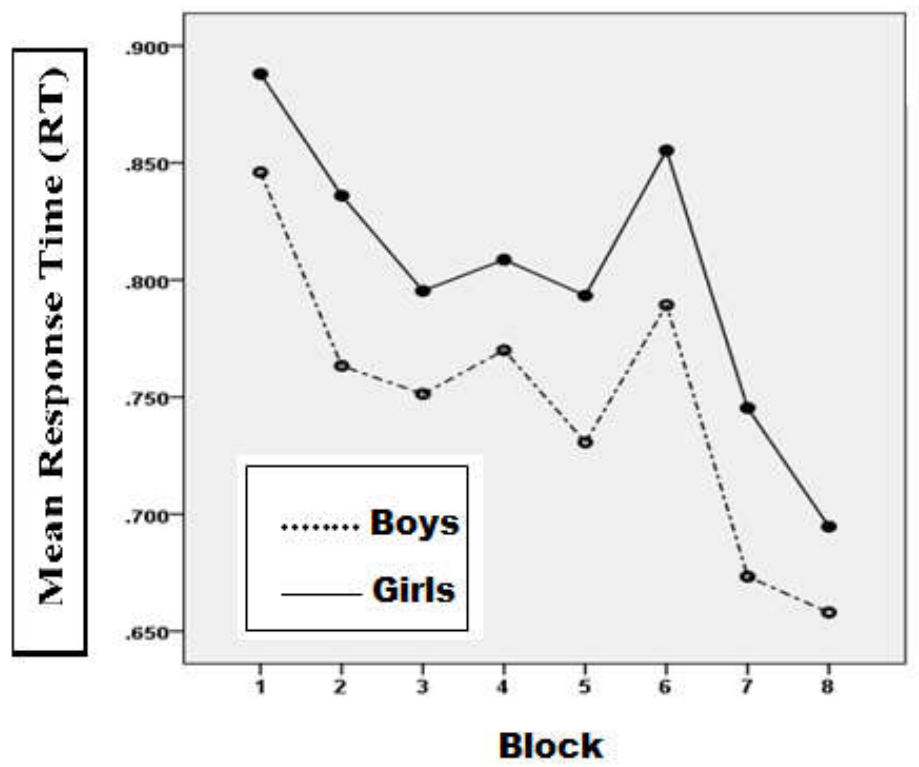

Figure 1. Mean response time (RT) in blocks for boys and girls.

\section{Discussion and Conclusion}

The present study aims at investigating the effect of gender (boy and girl) and type of stimulus (regular and irregular) on reaction time and accuracy. The results of analysis of variance showed that none of the variables of gender and type of stimulus had a significant effect on response accuracy. Also, according to the results, only the type of stimulus has a significant effect on response time and gender is also ineffective in this variable. Research on reaction time is more about simple and selective reaction time, and most studies have given more importance to response time. Therefore, the explanations will emphasize the response time more. The results of the present study regarding gender differences are inconsistent with the result of Shelton and Kumar (2010), Nikam and Godkari (2012), Devi and Mudhuri (2017), Maslovat et al (2019) and Wadoo et al (2019). All of these studies point to the effect of gender on simple and selective reaction time on the sample, and in none of them has the serial reaction time been studied. The male-female difference can be explained due to the lag between the presentation of the stimulus and the beginning of muscle contraction. It is documented in the literature that the muscle contraction time is the same for males and females (Botwinick \& Thompson, 1966). and motor responses in males are comparatively stronger than females (Silverman, 2006) this explains why males have faster simple RTs for both auditory as well as visual stimuli. Wadoo et al Believe that there is evidence of sex differences in developmental cerebral white and grey matter volume changes through adolescence and these are thought to reflect myelination and changes in synaptic density. Therefore, brain dimorphism is another mechanism that may underlie sex differences in RT variability. Maslovat et al (2019) also found that men reacted faster than women to both visual and auditory stimuli. On the other hand, the results of the present 
study consistent with the result of Kahn et al (2018). In this study, it was reported that gender had no effect on reaction time. Çakmakçı et al (2019) examined Does Once-a-Week Boxing Training Improve Strength and Reaction Time? The study found that even one-day boxing training in a week can improve in individuals' reaction time, and most sports lead to these improve. Pitch and Johnson (2012) also believe that women are more flexible than men in terms of training and benefit more from training than men. The interaction of the findings of these studies provides a valuable explanation. Considering that the sample of the present study was physical education students who practiced regularly in at least 6 sessions per week in different sports, can be said that it is possible that due to exercise, the gender difference has been reduced to an acceptable level. In other words, female athletes benefited more from their regular exercise and showed more flexibility than boys, which led to a greater reduction in their reaction time. In fact, this indicates that although girls have a higher reaction time than boys, but regular intervention and practice could have more positive effects in reducing their reaction time, until a non-significant difference between them becomes apparent. However, as reported in Figure 1, the mean response time was still lower in boys than in girls. The results of the present study also showed that the type of stimulus presentation regularly or irregularly in the serial reaction time blocks can have a significant effect. In fact, the results showed that regular stimulus could take less response time than irregular stimulus for both girls and boys.
These results are consistent with the findings of Abdoli et al (2004), Rose et al (2013) Maslovat et al (2019). Abdoli et al (2004) compared the effect of implicit and explicit learning on serial reaction time and showed that implicit learning can affect serial reaction time. In fact, the researchers presented two irregular exercise blocks that Feed forward group about the irregular presentation of the stimulus and the other group did not receive a Feed forward. Finally, it was found that there is a difference between regular and irregular stimulus presentation and the reaction time in irregular stimulus presentation is less than regular stimulus presentation. Rose et al (2013) acquired similar results to the findings of Abdoli et al However, in the research of Rose et al the intervention was performed as a neurofeedback training session, which showed that implicit learning can have positive effects on serial reaction time. In the present study, because blocks 1 and 6 were presented irregularly, the subjects still showed better performance in the sixth block than the first block. In fact, although the research sample was able to find out the sequence of stimulus presentation in regular blocks without Feed forward and show better performance through implicit learning than in irregular blocks. Again, in irregular blocks, they obtained less reaction time. Using implicit learning in regular blocks, subjects showed less reaction time than in irregular blocks as they progressed in blocks. Maslovat et al Also reported that the reaction time increases with the complexity of the response.

One of the limitations of the present study was the novelty of the research field. Also, the absence of a 
non-athlete group and its comparison with the athlete group is another limitation of the present study, which is finally suggested that in order to properly explain and generalize the results to other areas, the comparison and effect of gender between athletes and non-athletes should also be examined.

\section{References}

1. Abdoli, B., Ashayeri, H., Baqerzadeh, F., Farrokhi, A (2004). Comparison of the effect of latent and overt learning on chain reaction time. Move. 19, 23-40. [in persian]

2. Adleman, N. E., Chen, G., Reynolds, R. C., Frackman, A., Razdan, V., Weissman, D. H., et al. (2016). Agerelated differences in the neural correlates of trial-totrial variations of reaction time. Dev. Cogn. Neurosci, 19, 248-257.

3. Ali, B. B., Oueslati, O., \& Dugas, É. (2018). A Smart Wireless System for Modeling Visual Searching Behavior and Assessing Reaction Time in Sports and Rehabilitation Activities. International Conference on Biomedical Engineering and Applications (ICBEA), 1-6, IEEE.

4. Atan, T., \& Akyol, P. (2014). Reaction times of different branch athletes and correlation between reaction time parameters. Procedia-Social and Behavioral Sciences, 116, 2886-2889.

5. Balko, S., Simonek, J., Balko, I., Heller, J., Chytry, V., Balogova, K., \& Gronek, P. (2020). The influence of different caffeine doses on visual and audial reaction time with different delay from its consumption. Science \& Sports.

6. Bayless, DW., Darling, JS., Stout, WJ., Daniel, JM. (2012). Sex differences in attentional processes in adult rats as measured by performance on the 5-choice serial reaction time task. Behavioral Brain Research, 235, 4854.

7. Bennett, Natalie. (2011). Sex Differences in Intelligence Areas and Response Time Tasks. Honors Research Thesis. The Ohio State University.

8. Botwinick, J., \& Thompson, L. W. (1966). Components of reaction time in relation to age and sex. The Journal of genetic psychology, 108(2), 175-183.

9. Bruinsma, B., Terra, H., de Kloet, S. F., Luchicchi, A., Timmerman, A. J., Remmelink, E., ... \& Mansvelder, H. D. (2019). An automated home-cage-based 5-choice serial reaction time task for rapid assessment of attention and impulsivity in rats. Psychopharmacology, 236(7), 2015-2026.

10. Brychta, P., Hojka, V., Heller, J.A.N., Konarski, J.A.N.M., Coufalova, K., Ruda, T., 2013. A comparison of reaction times of boys and girls aged 10-11 and 14-15 years. Trends Sport.Sci 20 (3), 147-152.

11. Çakmakçı, E., Tatlıcı, A., Kahraman, S., Yıılmaz, S., Ünsal, B., \& Özkaymakoğlu, C. (2019). Does once-aweek boxing training improve strength and reaction time? Uluslararasi Sport Egzersiz ve Antrenman Bilimi Dergisi, 5(2), 88-92.

12. Der, G., \& Deary, I. J. (2006). Age and sex differences in reaction time in adulthood: Results from the United Kingdom Health and Lifestyle Survey. Psychology and Aging, 21(1), 62-73.

13. Dykiert, D., Hall, D., van Gemeren, N., Benson, R., Der, G., Starr, J.M., Deary, I.J., 2010. The effects of high altitude on choice reaction time mean and intraindividual variability: results of the Edinburgh Altitude Research Expedition of 2008. Neuropsychology 24 (3), 391.

14. Gómez-López, M., et al. (2017). Relative age effect in handball players of Spain. Journal of Physical Education and Sport, 17(2), 705-711. ISSN 2247-8051.

15. Greenhouse, I., King, M., Noah, S., Maddock, R. J., and Ivry, R. B. (2017). Individual differences in resting corticospinal excitability are correlated with reaction time and GABA content in motor cortex. J. Neurosci. 37, 2686-2696.

16. Hascelik, Z., Basg€oze, O., Türker, K., Narman, S., Ozker, R., 1989. The effects of physical training on physical fitness tests and auditory and visual reaction times of volleyball players. J. Sports Med. Phys. Fit. 29 (3), 234-239.

17. Hong, Y., Alvarado, R. L., Jog, A., Greve, D. N., \& Salat, D. H. (2020). Serial Reaction Time Task Performance in Older Adults with Neuropsychologically Defined Mild Cognitive Impairment. Journal of Alzheimer's Disease, (Preprint), 1-10.

18. Karia, R. M., Ghuntla, T. P., Mehta, H. B., Gokhale, P. A., \& Shah, C. J. (2012). Effect of gender difference on visual reaction time: A study on medical students of Bhavnagar region. IOSR Journal of Pharmacy, 2(3), 452-454.

19. Kozina, Z., et al. (2017). Comparative characteristics of psychophysiological indicators in the representatives of cyclic and game sports. Journal of Physical Education and Sport, 17(2), 648-655. ISSN 2247-8051.

20. Kuan, Y. M., Zuhairi, N. A., Manan, F. A., Knight, V. F., \& Omar, R. (2018). Visual reaction time and visual anticipation time between athletes and nonathletes. Malaysian Journal of Public Health Medicine, 1, 135-141.

21. Kuang, S. (2017). Is reaction time an index of white matter connectivity during training? Cognitive Neuroscience, 8(2), 126-128.

22. Lauridsen, M.M., Grønbæk, H., Næser, E.B., Leth, S.T., Vilstrup, H., 2012. Gender and age effects on the continuous reaction times method in volunteers and patients with cirrhosis. Metab. Brain Dis. 27 (4), 559565.

23. Le Mansec, Y., Dorel, S., Nordez, A., \& Jubeau, M. (2019). Is reaction time altered by mental or physical exertion? European journal of applied physiology, 119(6), 1323-1335.

24. Martin, F.H., Garfield, J., 2006. Combined effects of alcohol and caffeine on the late components of the eventrelated potential and on reaction time. Biol. Psychol. 71 (1), 63-73.

25. Maslovat, D., Klapp, S. T., Forgaard, C. J., Chua, R., \& Franks, I. M. (2019). The effect of response complexity 
on simple reaction time occurs even with a highly predictable imperative stimulus. Neuroscience Letters, 704, 62-66.

26. Nejati, V., Ashayeri, H., Grossi Farshi, M \& Aghdasi, M (2008). Investigating the role of knowing the sequence of motor sequences in learning it. Research in Sports Science, 15, 59-147. [in persian]

27. Nikam, L. H., \& Gadkari, J. V. (2012). Effect of age, gender and body mass index on visual and auditory reaction times in Indian population. Indian $J$ Physiol Pharmacol, 56(1), 94-99

28. Obetko, M., Babic, M., \& Peráček, P. (2019). Changes in disjunctive reaction time of soccer goalkeepers in selected training load zones. Journal of Physical Education and Sport, 19, 420-426.

29. Pancar, Z., Özdal, M., Pancar, S., \& Biçer, M. (2016). Investigation of visual and auditory simple reaction time of 11-18 aged youth. European Journal of Physical Education and Sport Science.

30. Pietsch, S., Jansen, P (2012). Different mental rotation performance in students of music, sport and education. Journal of Learning and Individual Differences, 22,159163.

31. Raichur, N., (2013) Assessment of Audio-Visual Reaction Time in drivers. Journal of Bioscience \& Technology, 4 (1), 508-512.

32. Ramanathan, M., Eswari, R., Bhavanani, A. B., Prathima, G. S., \& Sanguida, A. (2019). Yoga training enhances auditory and visual reaction time in children with autism spectrum disorder: A case-control study. SBV Journal of Basic Clinical and Applied Health Science, 2(1), 8-13.

33. Robertson EM. (2007)."The serial reaction time task: implicit motor skill learning". J Neuro science 27: PP:10073-10075.

34. Ros, T., Munneke, M.A.M., Parkinson, L.A., Gruzelie, J.H. (2013). Neurofeedback facilitation of implicit motor learning, 04.013, 95:54-8.

35. Sant'Ana, J., Franchini, E., da Silva, V., Diefenthaeler, F., 2017. Effect of fatigue on reaction time, response time, performance time, and kick impact in taekwondo roundhouse kick. Sports BioMech. 16 (2), 201-209.

36. Shelton, J., \& Kumar, G. P. (2010). Comparison between Auditory and Visual Simple Reaction Times. Neuroscience \& Medicine, 01 (01), 30-32.

37. Silverman, I. (2006). Sex differences in simple visual reaction time: A historical meta-analysis. Sex Roles, 54(1-2), 57-68.

38. Spierer, D., Petersen, R., Duffy, K., Corcoran, B. \& Rawls-Martin, T. (2010). Gender influence on response time to sensory stimuli. Journal of Strength and Conditioning Research, 24(4), 957-963.

39. Syamala Devi, Kala Madhuri N. (2017). Comparative study of visual and auditory reaction times on the basis of gender and physical activity levels of medical students. MedPulse International Journal of Physiology, 4(1) 04-06.

40. Wadoo, O. K., Sayeed, S. I., \& Rouf, M. (2019). Effect of Gender and Physical activity on Visual and Auditory reaction time in young Adults. International Journal, 2(2), 462.
41. Wang J. (2009). "Reaction-time training for elite athletes: a winning formula for champions". International Journal of Coaching Science, 3(2), 67-78.

42. Willingham, D. B., Wells, L. A., Farrell, J. M., \& Stemwedel, M. E. (2000). Implicit motor sequence learning is represented in response locations. Memory \& cognition, 28(3), 366-375. 